\title{
Estimation of storm runoff loads based on rainfall-related variables and power law models - Case study in Alexandra
}

\author{
Yaw Owusu-Asante* and David Stephenson \\ School of Civil and Environmental Engineering, University of the Witwatersrand, Private Bag 3, WITS 2050, South Africa
}

\begin{abstract}
This paper compares the use of simple regression equations of three commonly used pollutant build-up and wash-off functions, namely linear, power and exponential functions, to estimate event pollutant loads. The comparative study indicated that, event loads are better estimated as power functions of storm-related independent variables. On the notion that rainfall data are more readily available, easy and less expensive to collect than runoff data, the calibrated model was verified using rainfall volume as independent variable. The verified model was then used to develop load-duration-intensity curves to serve as predictive tools. Planners and engineers can use these predictive tools to obtain an approximate estimate of event pollutant loads in storm runoff from Alexandra (and also other townships with similar physical, land-use, climatic and hydraulic characteristics and water quality issues) for the purpose of managing or improving drainage conditions in the township.
\end{abstract}

Keywords: event loads, power functions, modelling, load-duration-intensity curves

\section{Introduction}

Inadequate sanitation and drainage is one of the major environmental and health problems facing high-density low-income settlements in South Africa today. The backlog in sanitation and drainage includes solid waste, sewage, grey-water and severely contaminated stormwater runoff. In these areas (as noted in Alexandra) the paths are often merged; sewage, greywater, solid waste and contaminated runoff enter surface drains, eventually discharging into streams, rivers and impoundments that are used for drinking water supply and recreation. These cause water quality problems, pose potentially serious human and environmental health risks through contact recreation and through the use of untreated water, result in high drinking water purification costs and cause a loss of amenity value and diminished recreation potential (Ashton and Bhagwan, 2001).

The unprecedented population growths in these settlements have severely strained the ability of municipalities to meet the need for drainage and treatment. As local governments have tried to cope with insufficient services, priority has been given generally to high-income areas where full or partial cost-recovery is considered feasible. Low-income areas are often left unserved or served by woefully inadequate drainage and treatment facilities. The principal reason for this situation is the high cost of conventional drainage and treatment practices. It is for this same reason that the Water Research Commission of South Africa initiated a project to look into appropriate technology options that are feasible for rural and peri-urban drainage. The project, among other things, seeks to identify potential management interventions (e.g. ponds, vegetated biofilters and wetlands) and appropriate technology for treating runoff and grey-water. To achieve this objective, a technique needs to be developed to estimate storm runoff loads in view of limited data available.

Previous studies conducted in South Africa have concentrated on the use of linear regression techniques/models to

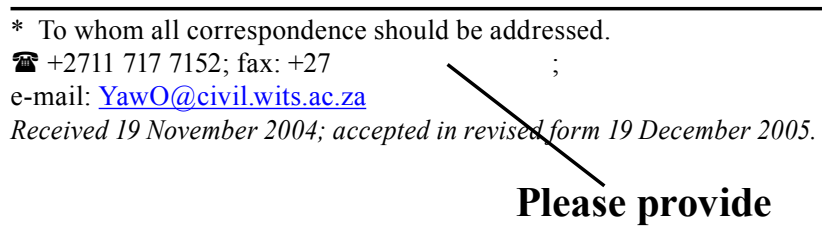

Available on website http://www.wrc.org.za

ISSN 0378-4738 = Water SA Vol. 32 No. 2 April 2006

ISSN 1816-7950 = Water SA (on-line) estimate storm loads. This paper compares three different regression models commonly used in pollutant load estimation. The best regression model (involving rainfall-related variables) is further used to develop load-duration-intensity (LDI) curves for prediction of storm runoff loads. Vase and Chiew (2003) also used rainfall-related variables to develop similar characteristic curves based on laboratory experimental runs using rainfall simulators. The data and information used in this paper were compiled by Wimberley (1992), which to date, stands out as one of the most comprehensive studies in South Africa that contribute meaningful data on the subject concerning water quality and flow measurements in urban settlements.

\section{Catchment description}

The Alexandra township is located $12 \mathrm{~km}$ north-east of central Johannesburg and $4 \mathrm{~km}$ east of Sandton central business district. The township is split into the west and east bank by the Jukskei River; the west bank is completely developed whereas the east bank is undeveloped. The west bank, which is principally the focus of this study covers a total surface area of about 350 ha. The official population of Alexandra is estimated as 166971 according to the 2001 population census of South Africa. This translates to a population density of 477 persons/ ha and $80 \mathrm{dwelling}$ units/ha (assuming 6 persons/dwelling unit). This suggests that every person in Alexandra has, on average, about $16 \mathrm{~m}^{2}$ of living space, accepting that roads, businesses, schools, and other open spaces take up $20 \%$ of the area. If the relatively small number of storeyed buildings in Alexandra is further taken into consideration, this figure becomes even more alarming.

Land-use characteristics are being dominated by a highdensity residential development. Stormwater drains service the township. Most of the drainage network consists of underground pipe network with an outfall into the Jukskei River. A waterborne sewage system services the formal settlements whereas in the informal settlements, sewage is removed in buckets, and taken to the Alexandra Sewage Works. The area slopes steeply in a west-east direction towards the Jukskei River, with slopes 
varying from $12.5 \%$ in the western sections to $3.3 \%$ in the sections closer to the Jukskei River. The average annual rainfall in the area is about $750 \mathrm{~mm}$.

\section{Data collection and analysis}

Data for this paper were collected in 1991 as part of a research project (Wimberley, 1992). Data from 16 storm events between August 1991 and November 1991 were monitored, where sequential discrete samples were collected over the hydrograph and the rainfall and runoff flow rates were concurrently measured. Rainfall intensity was calculated as total precipitation divided by rainfall duration. Runoff depth was calculated as runoff volume divided by the township area under study. The storm runoff mean concentration was determined by calculating the area under the load graph curve (concentration multiplied by discharge rate over time) and dividing it by the area under the hydrograph curve (runoff rate over time). The event load was calculated by multiplying event mean concentration by total event storm volume. Pollutants of concern analysed in the study included: chemical oxygen demand (COD); suspended solids (SS); total Kjeldahl nitrogen (TKN); ortho-phosphates $\left(\mathrm{PO}_{4}\right)$; total dissolved solids (TDS); chloride $(\mathrm{Cl})$; sulphate $\left(\mathrm{SO}_{4}\right)$; iron $(\mathrm{Fe})$; and lead $(\mathrm{Pb})$. Marais and Armitage (2003) have also indicated that pollution resulting from litter is of much concern in South Africa, and Alexandra is no exception.

\section{Results and discussion of data}

Tables 1, 2, and 3 present statistical summaries of storm rainfall, runoff, event mean concentration and event load data. The pollutant concentrations are comparable to those of raw sewage - detailed analysis of pollution extent is provided in Wimberley and Coleman (1993), Wimberley (1992) and Campbell (2001). Event mean concentrations and loads ranged over one or more orders of magnitude for all constituents. The high variation is indicated by large standard deviation, which in turn indicates that the mean is substantially larger than the median. Comparatively, large variation occurs in COD, suspended solids and TDS, moderate variation in the nutrients and minerals and lesser variation in the metals, especially lead. This variability may be real or result from sampling and analytical technique.

\section{Empirical modelling}

Commonly used pollutant build-up and wash-off functions are:

$$
\begin{array}{ll}
\text { Linear } & P=a t \\
\text { Power } & \mathrm{P}=\mathrm{at}^{\mathrm{b}} \\
\text { Exponential } & P=P_{o}\left(1-e^{-a t}\right) \\
\text { Michaelis- Menton } & P=P_{o}^{*} t /(a+t)
\end{array}
$$

where:

$a, b$, and $P_{o}$ are model parameters

$P$ is load

\begin{tabular}{|c|c|c|c|c|c|c|c|c|c|}
\hline \multicolumn{10}{|c|}{$\begin{array}{r}\text { TABLE } 3 \\
\text { Summary of monitored event me }\end{array}$} \\
\hline & $\begin{array}{l}\text { COD } \\
(\mathrm{kg})\end{array}$ & $\begin{array}{l}\text { SS } \\
(\mathrm{kg})\end{array}$ & $\begin{array}{l}\text { TKN } \\
(\mathrm{kg})\end{array}$ & $\begin{array}{l}\mathrm{PO}_{4} \\
(\mathrm{~kg})\end{array}$ & $\begin{array}{l}\text { TDS } \\
\text { (kg) }\end{array}$ & $\begin{array}{c}\mathrm{Cl} \\
(\mathrm{kg})\end{array}$ & $\begin{array}{l}\mathrm{SO}_{4} \\
(\mathrm{~kg})\end{array}$ & $\begin{array}{c}\mathrm{Fe} \\
(\mathrm{kg})\end{array}$ & $\begin{array}{c}\mathrm{Pb} \\
(\mathrm{kg})\end{array}$ \\
\hline No. of events & 16 & 16 & 16 & 16 & 16 & 16 & 16 & 16 & 16 \\
\hline Minimum & 243.94 & 585.82 & 11.96 & 1.19 & 119.06 & 16.10 & 35.07 & 0.58 & 0.24 \\
\hline Maximum & 15672.80 & 44317.72 & 535.54 & 25.20 & 4095.33 & 725.11 & 660.06 & 415.83 & 19.84 \\
\hline Median & 2263.14 & 5604.12 & 171.28 & 7.62 & 1466.21 & 257.24 & 174.82 & 154.64 & 3.01 \\
\hline Mean & 3243.82 & 10317.89 & 180.39 & 8.71 & 1550.85 & 256.12 & 271.22 & 141.65 & 5.53 \\
\hline St. dev. & 4187.93 & 11349.83 & 144.79 & 6.02 & 1107.35 & 201.40 & 213.47 & 125.25 & 6.34 \\
\hline
\end{tabular}

$t$ is time

\begin{tabular}{|l|r|r|r|r|r|}
\hline \multicolumn{7}{|c|}{ TABLE 1 } \\
\hline & $\begin{array}{c}\text { Rainfall } \\
\text { depth } \\
\text { (mm) }\end{array}$ & $\begin{array}{c}\text { Rainfall } \\
\text { dura- } \\
\text { tion } \\
\text { (min) }\end{array}$ & $\begin{array}{c}\text { Rainfall } \\
\text { max } \\
\text { rate } \\
(\mathbf{m m} / \mathbf{h})\end{array}$ & $\begin{array}{c}\text { Runoff } \\
\text { volume } \\
\left.\mathbf{( m}^{3}\right)\end{array}$ & $\begin{array}{c}\text { Run- } \\
\text { off } \\
\text { peak } \\
\left(\mathbf{m}^{3} / \mathbf{s}\right)\end{array}$ \\
\hline Minimum & 0.40 & 20 & 2.40 & 264.00 & 0.10 \\
\hline Maximum & 21.03 & 120 & 64.80 & 12601.00 & 5.15 \\
\hline Median & 3.81 & 64.17 & 12.00 & 2409.00 & 1.63 \\
\hline Mean & 7.12 & 71.03 & 23.60 & 4543.15 & 1.77 \\
\hline St. dev. & 6.84 & 27.37 & 23.87 & 4013.65 & 1.48 \\
\hline
\end{tabular}

\begin{tabular}{|l|c|c|c|c|c|c|c|r|r|r|}
\hline \multicolumn{10}{|c|}{ Summary of monitored event mean concentration data } \\
\hline & $\begin{array}{c}\text { COD } \\
(\mathbf{m g} / \mathbf{l})\end{array}$ & $\begin{array}{c}\mathbf{S S} \\
(\mathbf{m g} / \mathbf{l})\end{array}$ & $\begin{array}{c}\text { TKN } \\
(\mathbf{m g} / \mathbf{\ell})\end{array}$ & $\begin{array}{c}\mathbf{P O}_{4} \\
(\mathbf{m g} / \mathbf{l})\end{array}$ & $\begin{array}{c}\text { TDS } \\
(\mathbf{m g} / \mathbf{\ell})\end{array}$ & $\begin{array}{c}\mathbf{C l} \\
(\mathbf{m g} / \mathbf{l})\end{array}$ & $\begin{array}{c}\mathbf{S O}_{4} \\
(\mathbf{m g} / \mathbf{l})\end{array}$ & $\begin{array}{c}\mathbf{F e} \\
(\mathbf{m g} / \mathbf{l})\end{array}$ & $\begin{array}{c}\mathbf{P b} \\
(\mathbf{m g} / \mathbf{l})\end{array}$ \\
\hline No. of events & 16 & 16 & 16 & 16 & 16 & 16 & 16 & 16 & 16 \\
\hline Minimum & 67.70 & 818.00 & 7.10 & 0.60 & 153.00 & 29.00 & 23.40 & 0.90 & 0.20 \\
\hline Maximum & 11440.00 & 7803.00 & 103.10 & 8.30 & 1273.00 & 301.00 & 213.00 & 102.00 & 31.00 \\
\hline Median & 578.20 & 2219.00 & 43.20 & 2.50 & 325.00 & 51.00 & 73.70 & 30.10 & 0.80 \\
\hline Mean & 1595.11 & 2855.23 & 50.88 & 3.10 & 480.38 & 78.53 & 81.21 & 34.01 & 3.53 \\
\hline St. dev. & 3073.82 & 2248.59 & 26.45 & 2.30 & 330.26 & 74.75 & 59.85 & 26.88 & 8.70 \\
\hline
\end{tabular}




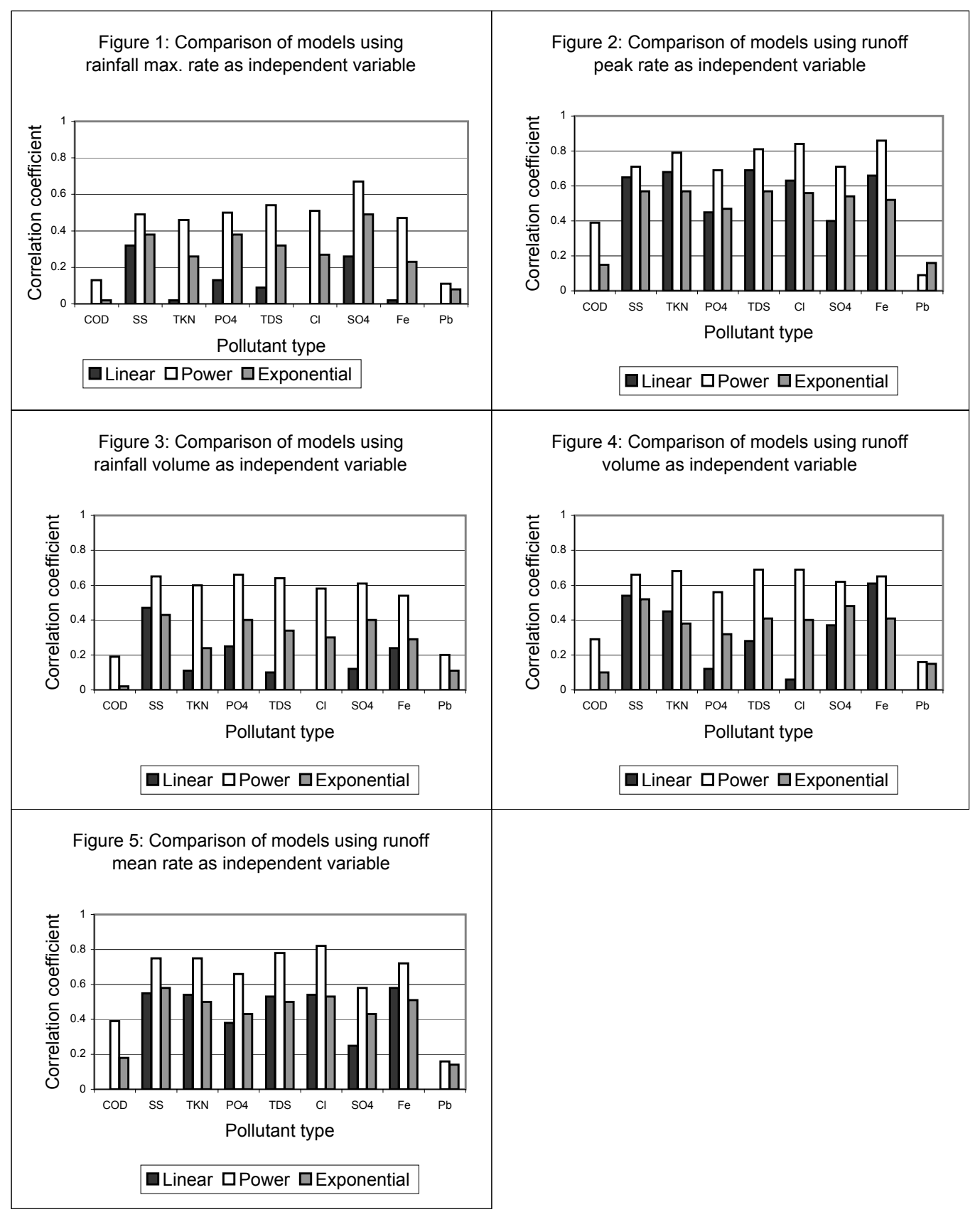

Previous studies conducted in South Africa have concentrated on the use of linear regression technique/model to estimate storm loads. The use of linear, power and exponential regression models is investigated to determine which function better fits the data distribution. A comparative study of the results of the simple regression models indicates that the event loads are better estimated as power functions (Eqs. (1) to (5), where $a$, and $b$ are model parameters) of rainfall volume, runoff volume, rainfall peak intensity, runoff peak rate and runoff mean rate. Figures 1 to 5 compare the correlation coefficients for the three functions, with power functions displaying higher correlation coefficient.

$$
\begin{aligned}
\text { Load } & =a(\text { rainfall volume })^{b} \\
\text { Load } & =a(\text { runoff volume })^{b} \\
\text { Load } & =a(\text { rainfall peak rate })^{b} \\
\text { Load } & =a(\text { runoff peak rate })^{b} \\
\text { Load } & =a(\text { runoff mean rate })^{b}
\end{aligned}
$$

The reason for the power function to better fit the rainfallrelated variables may be due to the fact that the power function applies to a system when large is rare and small is common. Like rainfall, most frequent recurrent rainfall events are small whereas large storms have infrequent recurrence. Perhaps correlation may favour linear and exponential functions where the independent variables are non-related rainfall variables, e.g. number of antecedent dry days, land-use variables, physical variables, and other catchment variables.

\section{Discussion of model estimates (calibration)}

Correlation coefficients $\left(\mathrm{R}^{2}\right)$ were calculated between event loads and rainfall-related variables to determine whether these parameters could be used to create predictive models using readily obtainable storm-related information. $\mathrm{R}^{2}$ indicates the 


\begin{tabular}{|c|c|c|c|c|c|c|}
\hline \multicolumn{7}{|c|}{$\begin{array}{c}\text { TABLE } 4 \\
\text { Summary of statistical parameters of per cent error of estimation for each } \\
\text { independent variable }\end{array}$} \\
\hline \multirow{2}{*}{$\begin{array}{l}\text { Independ- } \\
\text { ent vari- } \\
\text { able }\end{array}$} & \multirow{2}{*}{\begin{tabular}{|l} 
Pollutant \\
type
\end{tabular}} & \multicolumn{5}{|c|}{ Per cent error of estimation } \\
\hline & & Minimum & Maximum & Median & Mean & $\begin{array}{l}\text { Standard } \\
\text { deviation }\end{array}$ \\
\hline \multirow{9}{*}{$\begin{array}{l}\text { Rainfall } \\
\text { volume }\end{array}$} & COD & -76.2 & 377.0 & 55.2 & 65.2 & 126.2 \\
\hline & SS & -68.6 & 173.5 & -2.0 & 20.2 & 76.7 \\
\hline & TKN & -52.0 & 376.2 & -5.1 & 27.0 & 114.8 \\
\hline & $\mathrm{PO}_{4}$ & -61.5 & 90.9 & -14.2 & 10.2 & 49.0 \\
\hline & TDS & -69.4 & 95.3 & 11.5 & 14.8 & 56.0 \\
\hline & $\mathrm{Cl}$ & -80.1 & 108.3 & 2.2 & 19.1 & 62.3 \\
\hline & $\mathrm{SO}_{4}$ & -70.7 & 172.4 & -5.0 & 20.4 & 75.8 \\
\hline & $\mathrm{Fe}$ & -78.4 & 24433.4 & -20.7 & 189.4 & 678.9 \\
\hline & $\mathrm{Pb}$ & -92.7 & 293.5 & 2.4 & 66.1 & 145.9 \\
\hline \multirow{9}{*}{$\begin{array}{l}\text { Rainfall } \\
\text { max. rate }\end{array}$} & COD & -77.9 & 363.6 & 64.4 & 78.8 & 142.0 \\
\hline & SS & -71.1 & 312.8 & 3.0 & 34.0 & 111.3 \\
\hline & TKN & -60.7 & 302.6 & -21.9 & 35.9 & 119.7 \\
\hline & $\mathrm{PO}_{4}$ & -60.8 & 180.0 & 0.5 & 17.3 & 70.7 \\
\hline & TDS & -57.8 & 255.8 & -18.0 & 24.6 & 97.4 \\
\hline & $\mathrm{Cl}$ & -65.1 & 287.1 & -22.3 & 30.1 & 112.0 \\
\hline & $\mathrm{SO}_{4}$ & -61.4 & 133.3 & -3.0 & 16.9 & 65.3 \\
\hline & $\mathrm{Fe}$ & -83.2 & 1989.3 & -29.4 & 188.9 & 581.4 \\
\hline & $\mathrm{Pb}$ & -91.9 & 575.5 & 17.5 & 85.0 & 201.0 \\
\hline \multirow{9}{*}{$\begin{array}{l}\text { Runoff } \\
\text { volume }\end{array}$} & COD & -75.6 & 284.2 & 29.7 & 60.2 & 115.0 \\
\hline & SS & -69.0 & 142.8 & 8.7 & 16.9 & 62.4 \\
\hline & \begin{tabular}{|l|} 
TKN \\
\end{tabular} & -52.9 & 344.2 & -10.7 & 22.2 & 103.5 \\
\hline & $\mathrm{PO}_{4}$ & -58.9 & 132.3 & 4.3 & 12.9 & 56.4 \\
\hline & TDS & -67.4 & 84.0 & 15.8 & 12.9 & 51.7 \\
\hline & $\mathrm{Cl}$ & -78.8 & 70.2 & 7.3 & 12.9 & 45.4 \\
\hline & $\mathrm{SO}_{4}$ & -68.5 & 218.4 & -5.9 & 21.2 & 80.4 \\
\hline & $\mathrm{Fe}$ & -80.1 & 1474.2 & -12.2 & 108.3 & 414.8 \\
\hline & $\mathrm{Pb}$ & -92.8 & 339.6 & 5.1 & 70.5 & 153.2 \\
\hline \multirow{8}{*}{$\begin{array}{l}\text { Runoff } \\
\text { mean rate }\end{array}$} & COD & -69.0 & 310.9 & 36.0 & 59.3 & 113.9 \\
\hline & SS & -58.2 & 118.1 & 5.4 & 15.0 & 60.6 \\
\hline & TKN & -52.2 & 264.9 & -4.4 & 17.2 & 84.6 \\
\hline & $\mathrm{PO}_{4}$ & -54.7 & 93.8 & 0.1 & 10.6 & 48.9 \\
\hline & TDS & -46.8 & 178.7 & -12.3 & 11.0 & 60.7 \\
\hline & $\begin{array}{ll}\mathrm{Cl} \\
\end{array}$ & -56.6 & 133.9 & 5.4 & 8.7 & 48.8 \\
\hline & $\mathrm{SO}_{4}$ & -65.4 & 231.9 & -9.3 & 23.4 & 87.6 \\
\hline & $\mathrm{Fe}$ & -65.0 & 1129.4 & 1.3 & 91.2 & 332.2 \\
\hline \multirow{10}{*}{$\begin{array}{l}\text { Runoff } \\
\text { peak rate }\end{array}$} & $\mathrm{Pb}$ & -93.2 & 372.0 & 27.5 & 68.9 & 150.8 \\
\hline & COD & -68.4 & 290.5 & 23.2 & 58.9 & 113.1 \\
\hline & SS & -53.5 & 150.0 & -1.8 & 18.4 & 72.3 \\
\hline & TKN & -44.2 & 222.5 & -9.3 & 14.0 & 73.5 \\
\hline & $\mathrm{PO}_{4}$ & -56.1 & 88.9 & 4.6 & 9.4 & 45.7 \\
\hline & TDS & -52.4 & 116.3 & 0.3 & 8.5 & 47.8 \\
\hline & $\mathrm{Cl}$ & -61.2 & 77.6 & 1.3 & 7.3 & 39.8 \\
\hline & $\mathrm{SO}_{4}$ & -59.3 & 191.2 & -10.2 & 16.7 & 73.7 \\
\hline & $\mathrm{Fe}$ & -62.3 & 311.1 & -6.9 & 29.1 & 108.1 \\
\hline & $\mathrm{Pb}$ & -93.2 & 465.0 & 9.7 & 81.4 & 183.2 \\
\hline
\end{tabular}




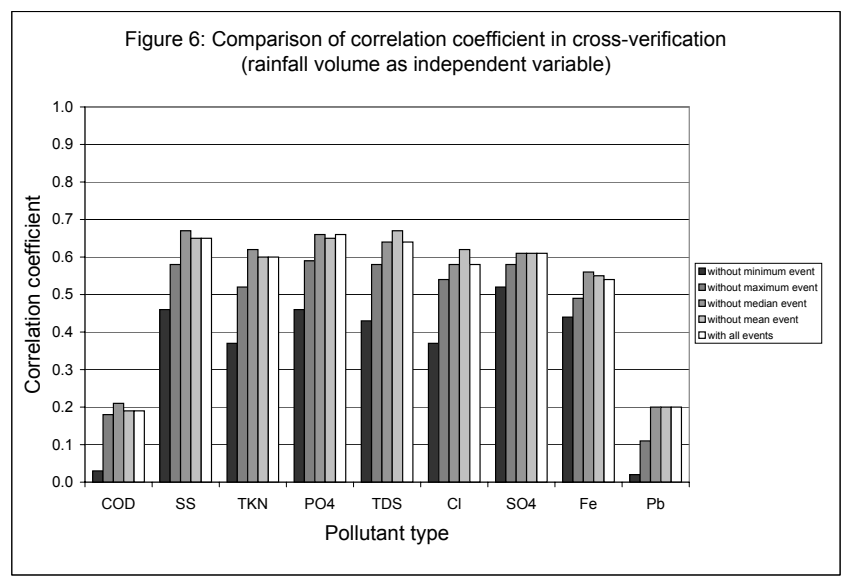

proportion of the total variation of the event load (dependent variable) that is explained by the rainfall-related variables (independent variables). Therefore, the value of $\mathrm{R}^{2}$ is used as a summary measure to judge the fit of the regression model to the data. Generally, runoff peak rate seems to provide larger $\mathrm{R}^{2}$ compared to the other independent rainfall-related variables, while $\mathrm{COD}$ and $\mathrm{Pb}$ are least correlated in all the models.

The relative accuracy of the power function model is only determined in this paper due to its relative superiority over linear and exponential functions. The accuracy is represented by per cent error of estimation, which is a measure of how well the regression models estimate pollutant loads of calibrated events. The per cent error of estimation for each pollutant in each storm event is defined as:

$$
P E E=100 \times\left(\frac{E s t-O b s}{O b s}\right)
$$

where:

Est and $O b s$ are the estimated and observed loads respectively.

Table 4 presents a summary of statistical parameters of per cent error of estimation for each independent variable. Apart from $\mathrm{Fe}$, which showed a very high range, the mean of the estimated error ranged from 7.3 to 85 per cent for the rest of the pollutant types.

\section{Discussion of model testing (prediction)}

The model was tested to determine its soundness by cross-verification method where four events were left out in turn, and the model was calibrated separately against the other events data. Regression analysis done separately in this way yielded new regression (calibration) models very similar to the original models wherein all the storm events were used. The load for the event that had been left out was then predicted and compared with the observed load. The relative accuracy of the power function model was again tested by per cent error of prediction, which in contrast, is a measure of how well the regression models estimate each pollutant load of non-calibrated events. The range of per cent error of prediction (PEP), calculated in the same way as per cent error of estimation, is also very similar to the range of PEE shown above. Figure 6 presents a comparison of correlation coefficients for the pollutants in the cross-verification testing for the model involving rainfall volume as independent variable. The four events: 15/11/91, 16/10/91, 27/11/91 and 9/11/91 corresponding to minimum, maximum, median and mean rainfall volume respectively were used in turn in the cross-verification testing.
TABLE 7

Calculation of SS pollutant loads for $10 \mathrm{~mm} / \mathrm{h}$ storm intensity

\begin{tabular}{|c|c|c|c|c|c|}
\hline \multirow{2}{*}{$\begin{array}{l}\text { Rain- } \\
\text { fall } \\
\text { dura- } \\
\text { tion } \\
\text { (min) }\end{array}$} & \multirow{2}{*}{$\begin{array}{l}\text { Rain- } \\
\text { fall in- } \\
\text { tensity } \\
(\mathrm{mm} / \mathrm{h})\end{array}$} & \multirow{2}{*}{$\begin{array}{l}\text { Rainfall } \\
\text { volume } \\
(\mathrm{x}),\left(\mathrm{m}^{3}\right)\end{array}$} & \multirow[t]{2}{*}{$\begin{array}{l}\text { Pollutant } \\
\text { load model }\end{array}$} & \multicolumn{2}{|c|}{$\begin{array}{l}\text { Predicted } \\
\text { pollutant load }\end{array}$} \\
\hline & & & & (kg) & $\left(\mathrm{mg} / \mathrm{m}^{2}\right)$ \\
\hline 10 & 10 & 2700 & \multirow{12}{*}{$y=\underset{0.76}{7.63 x}$} & 3093 & 1909 \\
\hline 20 & 10 & 5400 & & 5238 & 3233 \\
\hline 30 & 10 & 8100 & & 7128 & 4400 \\
\hline 40 & 10 & 10800 & & 8870 & 5475 \\
\hline 50 & 10 & 13500 & & 10509 & 6487 \\
\hline 60 & 10 & 16200 & & 12071 & 7451 \\
\hline 70 & 10 & 18900 & & 13572 & 8378 \\
\hline 80 & 10 & 21600 & & 15021 & 9272 \\
\hline 90 & 10 & 24300 & & 16428 & 10141 \\
\hline 100 & 10 & 27000 & & 17798 & 10986 \\
\hline 110 & 10 & 29700 & & 19135 & 11811 \\
\hline 120 & 10 & 32400 & & 20443 & 12619 \\
\hline
\end{tabular}

\section{Load-duration-intensity curves for event pollutant load prediction}

The pollutant wash-off loads from the data collected and modelled are presented as load-duration-intensity (LDI) curves. The relationship between pollutant loads per unit area and rainfall duration is plotted on the basis of the catchment-modelled data for different rainfall intensities. The y-axis representing the predicted pollutant load is expressed in $\mathrm{mg} / \mathrm{m}^{2}$. In this way, although the data were monitored for the southern catchment area of 162 ha, the curves can be applied to the entire Alexandra catchment. Loads per $\mathrm{m}^{2}$ predicted from the curves would then be multiplied by the total area ( $350 \mathrm{ha})$ to obtain the total load in $\mathrm{mg}$ or $\mathrm{kg}$ for Alexandra. This was based on the assumption that the characteristics (climatic, hydrological, physical, land-use, environmental and social parameters) of the southern catchment are similar or representative of the whole Alexandra catchment. Nevertheless, since the catchment area of Alexandra is relatively small, this assumption seems reasonable.

For a specified storm duration and intensity, storm volume $(\mathrm{mm})$ was evaluated, and using the tested power function model involving rainfall volume as independent variable (Eq.(1)), the 

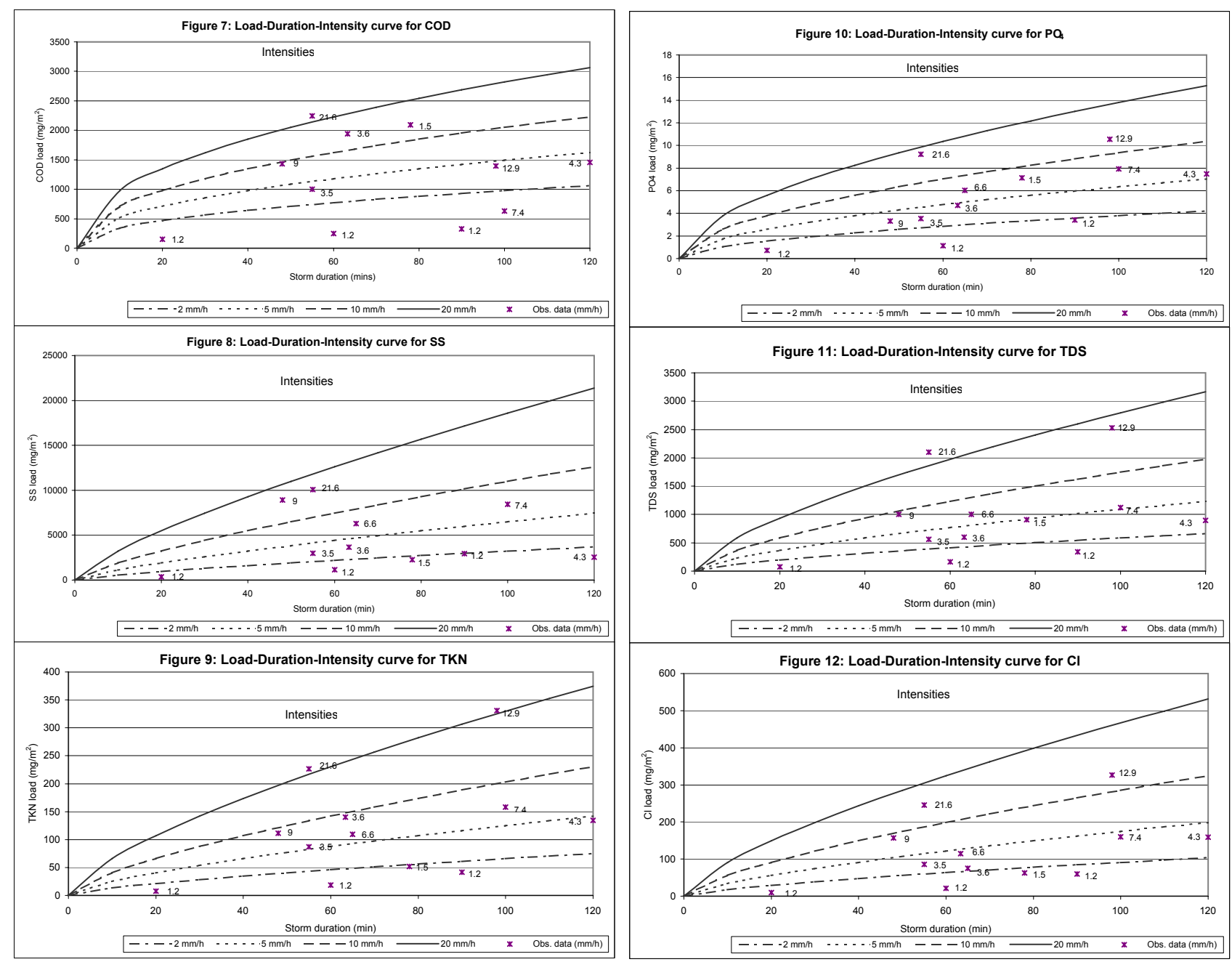

pollutant loads were predicted and subsequently used to prepare the characteristic curves. For example, for a mean storm intensity of $10 \mathrm{~mm} / \mathrm{h}$, the suspended solids pollutant loads for different storm durations are evaluated as summarised in Table 5 where the model parameters in Eq. (1) are determined as $a=7.63$ and $b=0.76$.

Rainfall-related variables were used to create the predictive tools (LDI curves) instead of runoff data because the former is readily available, or easy and less expensive to collect. The curves displayed in Figs. 7 to 15, depict increases in loads with increases in both storm duration and intensity as physically expected. Generally, the slope of the curves decreases with time, tending to flatten out at higher storm duration, suggesting that there is a limiting pollutant load that can be washed off by storm events. The monitored event durations and pollutant loads are also plotted in Figs. 7 to 15 to fit the corresponding event intensities. While most of the monitored data plot in the 'appropriate' positions (at or close to the modelled intensities) some of them do not. The disparities may be accounted for by the per cent error of estimations shown in Table 4 under rainfall volume.

\section{Conclusion}

This paper compares the use of simple regression equations of three commonly used pollutant build-up and wash-off functions, namely linear, power and exponential functions to estimate event pollutant loads. The comparative study indicated that

event loads are better estimated as power functions of rainfall and runoff volumes and rates (as independent variables). On the notion that rainfall data are more readily available, easier and less expensive to collect than runoff data, the calibrated model was verified using rainfall volume as independent variable. The verified model was then used to develop load-duration intensity curves to serve as predictive tools. Hence, for a selected design storm for a treatment facility (e.g. ponds, vegetated biofilters and wetlands) to be designed, the various pollutant loads can be predicted for the size of catchment area discharging into that treatment facility. With knowledge of the runoff volume (from the selected design storm) and the predicted event pollutant loads, event-mean concentrations into the treatment facility can also be determined.

\section{Acknowledgements}

The authors gratefully acknowledge financial assistance from the Water Research Commission, Pretoria, South Africa.

\section{References}

ASHTON PJ and BHAGWAN JN (2001) Guidelines for the Appropriate Management of Urban Runoff in South Africa. Integrated Report. WRC Report No. TT 155/01. Water Research Commission, Pretoria, South Africa.

CAMPBELL LA (2001) A Study on the Fate of Urban/Stormwater Runoff from Alexandra Township in the Jukskei River. WRC Report No. 598/3/01. Water Research Commission, Pretoria, South Africa. 


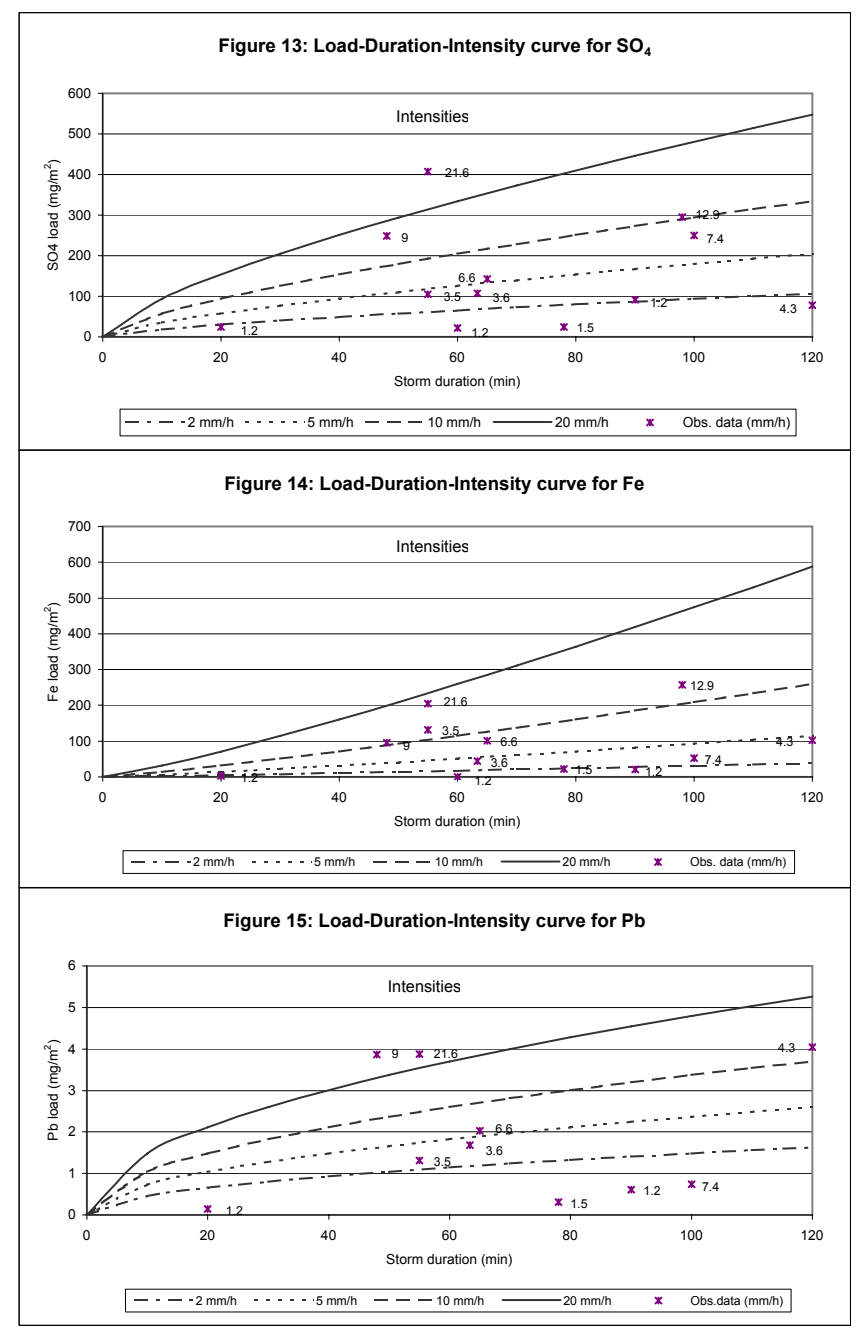

MARAIS M and ARMITAGE N (2003) The Measurement and Reduction of Urban Litter Entering Stormwater Drainage Systems. WRC Report No. TT 211/03. Water Research Commission, Pretoria, South Africa.

VASE J and CHIEW FHS (2003) Study of pollutant wash-off from small impervious experimental plots. Water Resour. Res. 39 (6) 1160.
WIMBERLEY FR (1992) The Effect of Polluted Stormwater Runoff from Alexandra Township on the Water Quality of the Jukskei River. M.Sc. Thesis, University of the Witwatersrand, Johannesburg, South Africa.

WIMBERLEY FR and COLEMAN TJ (1993) The effect of different urban development types on stormwater runoff quality: A comparison between two Johannesburg catchments. Water SA 19 (4) 325-330. 
Available on website http://www.wrc.org.za ISSN 0378-4738 = Water SA Vol. 32 No. 2 April 2006 ISSN 1816-7950 = Water SA (on-line) 